\title{
JOAQUín MORENO PEDROSA, Poesía y poética de Antonio Car- vajal. Padilla Editores \& Libreros, Sevilla, 2007.
}

$\mathrm{E}$ $\mathrm{N}$ la colección Cuadernos de Teoría de la literatura, que dirige Esteban Torre, Joaquín Moreno, profesor del Área de Teoría de la Literatura y Literatura Comparada de la Universidad de Sevilla, ha publicado Poesía y poética de Antonio Carvajal. En este libro se ofrece una visión rica y detallada de los aspectos más importantes de la obra del poeta granadino. Su hábil manejo de las formas métricas, referido casi siempre por la crítica como uno de los grandes valores de su poesía, es estudiado y situado desde la doble concepción que posee de poeta e investigador. Joaquín Moreno va desgranando a lo largo del libro la relación entre la labor crítica y la creación poética de Antonio Carvajal, mostrando una imagen coherente de su obra.

El primer capítulo está dedicado a la contextualización y la biografía del poeta. La poesía de Antonio Carvajal presenta una particular problematización para ser contextualizada dentro de la poesía española del siglo XX. Su estilo personal y su independencia respecto a los principales grupos poéticos hacen que sea muy difícil situarlo dentro de una corriente definida. Su poesía no atiende a los modelos ni a las modas de su época, como expone Joaquín Moreno al hilo de una acertada revisión sobre la poesía social y, posteriormente, sobre el fenómeno de los novísimos. Al considerar el contexto poético, Joaquín Moreno va entrelazando los datos vitales con la trayectoria literaria del poeta, desarrollando una lectura que va más allá de lo meramente biográfico. Prestando una gran atención a las tradiciones y a las influencias de su poesía y centrando al lector desde el principio en la dependencia entre tradición y originalidad, separa los modelos que tomó como guías para su aprendizaje, como José Hierro, Blas de Otero o Pablo García Baena, de las influencias centrales en su poesía, como Garcilaso de la Vega, Góngora o Federico García Lorca, entre otros. Añade a la interpretación clásica de la poesía de Carvajal, como obra anclada en los modelos barrocos, otros modelos fundamentales para su estudio, puntualizando y matizando la comprensión de su poesía, al explicitar las lecturas de otros clásicos, como Horacio o Virgilio, y de poetas modernos del siglo XX, como Guillén o Aleixandre.

El segundo capítulo es especialmente útil para los interesados en el campo de la teoría de la literatura y de la métrica. Según muestra Joaquín Moreno, apoyándose en textos teóricos y manifestaciones del escritor, su concepción poética parece girar en torno a ciertas ideas provenientes del ámbito de la 
teoría de la música. Estas ideas son exportadas como conceptos poéticos, aunque no siempre resultan rigurosos. El origen de la importancia de la música para el poeta, vendría del temprano estudio que realiza para su tesis doctoral del Arte Métrica Elemental de Miguel Agustín Príncipe, que el poeta asimila como concepción válida para sus estudios críticos. Tras precisar el término "poesía" con el que opera discursivamente Antonio Carvajal, y manifestando previamente la disposición del poeta a no elaborar reflexiones sistematizadas, entiende que el poeta no aspira como crítico a ningún tipo de validez universal, y que, al usar el término poesía, abarca dos sentidos referidos tanto a la belleza como a la técnica con la que se plasma lingüísticamente en el poema. Respecto a la imagen del poeta que Antonio Carvajal proyecta en sus estudios críticos y en sus propios poemas, se ofrece una visión realista y honesta de la labor del poeta, alejado de los tópicos decadentistas, para definir al poeta como un orfebre que está muy atento a la corrección y a la realización concreta de su obra. Por lo que concierne a la métrica y a la retórica, lejos de ser artificios banales o añadidos al poema, serían el cauce necesario para la expresión poética.

En el apartado sobre la oralidad y "musicalidad" de la poesía en Antonio Carvajal, se estudian los aspectos métricos de su obra y de sus concepciones críticas. Joaquín Moreno nos señala la importancia que tiene el ritmo para Antonio Carvajal, comprendido, en su caso, siempre desde la importancia del papel de la oralidad y de la música, hasta el punto que, al recitar los poemas llega a alterar la disposición versal, por estimar la estrofa, y no el verso, como el elemento regulador primario del poema. Esta particularidad se debería, argumenta Joaquín Moreno, a una posible confusión del alcance de los conceptos musicales, que hereda, como señalamos más arriba, de Miguel Agustín Príncipe, al seguir una supuesta línea melódica en vez del metro silábico como patrón rector del poema.

A lo largo de sus estudios, Antonio Carvajal ha ido modificando algunas de sus posturas, pero, al inicio de sus reflexiones, hay algunos aspectos no muy claros en su conceptualización de la poesía, como el concepto de "duración". En este sentido, Príncipe considera como "ley suprema" de la versificación española el "compás", elemento de carácter musical difícilmente aplicable a la poesía, lo que también acarrea problemas respecto a la comprensión del funcionamiento de la acentuación, al subdividir los versos en "pies de compás", acercándose al modelo de Tomás Navarro Tomás. Son confusiones que Joaquín Moreno va desmontando, siguiendo los estudios de Esteban Torre en El ritmo del verso (Universidad de Murcia, Murcia, 1999), para que el lector acabe teniendo un panorama claro y definido de las aportaciones conceptuales de Antonio Carvajal en relación a las últimas teorías sobre el ritmo del verso. El mismo poeta, al variar su postura crítica, se acerca acertadamente al concepto de verso como unidad rítmica fundamental, pero sigue albergando dudas en el concepto de "duración" y sigue hablando, en el 2003, de sílabas breves y largas. Una vez que ha analizado los conceptos críticos de Antonio Carvajal y establecido las posibles soluciones a algunas 
confusiones, Joaquín Moreno se centra en la imagen del poeta como innovador métrico o como continuador de la tradición. Y mientras que Antonio Carvajal se ve a sí mismo como un "innovador métrico", Joaquín Moreno presenta un poeta que no se aparta demasiado de la tradición. Si tenemos en cuenta el elevado número de poetas españoles del siglo XX que manejan un número reducido de versos, podemos entender que Antonio Carvajal se entienda a sí mismo como una excepción. Pero si atendemos, como hace Joaquín Moreno, al número de metros que maneja Antonio Carvajal y que no se han usado antes en la tradición, quizás sea exagerado considerarlo un innovador. Porque la ruptura de la versificación tradicional que lleva a cabo el poeta granadino parte siempre de los metros clásicos. Incluso puede hacerse esta afirmación a pesar de algunos casos de verso libre que Joaquín Moreno, siguiendo la obra de María Victoria Utrera Historia y teoría del verso libre (Padilla Libros, Sevilla, 2001), considera que muestran una clara regularidad, basada generalmente en el ritmo de tipo endecasilábico.

El tercer capítulo del libro está estructurado en torno al problema de la función de la poesía. Para Antonio Carvajal, la labor del poeta reside en su compromiso estético. La naturaleza, como ámbito de esplendor, o como jardín para relacionarse con los hombres, la amistad y el amor son algunos de los temas fundamentales en los que articula Antonio Carvajal su actitud como poeta ante el mundo. La atención al lector como dueño de la obra, una vez publicada, y la proyección que la obra toma, una vez entregada a las diversas lecturas que de ella se realicen, no colocan a al poeta en una posición de relativismo absoluto, por más que existan algunos tintes relativistas. Aunque la ética y el compromiso político no condicionen su poesía, su idea de la honestidad poética como "autenticidad" no le permite escribir poemas desde cualquier posicionamiento ideológico; entiende el poema como una obra de cara a la humanidad, que, si bien no interesará a la mayoría, debe aportarle algo de calidad a la minoría que por él se interese.

Para cerrar el libro, Joaquín Moreno nos ofrece un interesante epílogo, en el que se resumen y se redefinen los resultados de su investigación, ofreciendo una imagen precisa y sugerente de la obra de Antonio Carvajal y formulando, en un claro recorrido, el transcurso de la poesía española de la segunda mitad del siglo XX, desde la poesía social hasta la consolidación de la obra poética de Carvajal. Completa este trabajo monográfico una completa bibliografía sobre el poeta y una adecuada bibliografía general. Se trata, en definitiva, de una monografía compleja y rigurosa sobre la obra de un poeta consolidado, que va más allá del interés particular en este poeta, al trazar un recorrido teórico en el que se examinan cuestiones fundamentales de métrica y teoría del ritmo. 